\title{
Review of medal predictions for South Africa in the Delhi 2010 Commonwealth Games
}

\author{
Girish M Ramchandani (MSc) \\ Darryl J Wilson (MSc) \\ Sport Industry Research Centre, Sheffield Hallam University, Sheffield, UK
}

\begin{abstract}
Objectives. This paper reviews South Africa's performance in the Delhi 2010 Commonwealth Games relative to predicted medal success. Methods. Forecasts based on the nation's previous success are compared against medals won in Delhi.

Results. Actual performance is in line with predicted performance in terms of gold medals but total medals won are below expectations. Conclusion. The findings are of potential value to relevant sports authorities and follow up research is proposed.
\end{abstract}

\section{Introduction}

This paper reviews South Africa's recent performance in the Delhi 2010 Commonweath Games relative to the medal forecasts undertaken for the nation prior to the event. ${ }^{1}$ The initial research was a relatively novel concept given that host nations in the Olympic Games have almost exclusively been the focus of performance predictions. ${ }^{2-5}$ Moreover, forecasts often tend to be made on the basis of macroeconomic variables such as population and gross domestic product, ${ }^{2,3}$ with little attention given to a nation's traditional sporting prowess.

\section{Methods}

The methodology used to make the forecasts for South Africa in Delhi 2010 is documented in the original research paper. ${ }^{1}$ In short, the forecasts were based on different scenarios which took into account South Africa's previous performances in the event since rejoining the Commonwealth in 1994. Forecasts were constructed on a sport-by-sport basis and overall. Post Delhi 2010, the actual performance of South African athletes was scrutinised alongside the forecasts. This provided an indication of the accuracy of the predicted performance and practical implications of the research.

\section{Results}

Table I provides a comparative view of South Africa's performance in the Commonwealth Games on a sport-by-sport basis and overall relative to

\section{CORRESPONDENCE:}

Girish M Ramchandani

Sport Industry Research Centre

Sheffield Hallam University

A118 Collegiate Hall

Collegiate Crescent

Sheffield S10 2BP

UK

Tel: +44 (0) 1142255461

E-mail: g.ramchandani@shu.ac.uk the number of gold medals and total medals predicted. The data presented in Table I can be categorised into four clusters, as outlined below.

\section{Cluster 1: Performance within the predicted range}

South Africa's gold medal performance in Delhi was within the predicted range for 13 out of the 17 sports and overall. Moreover, the forecast was accurate at predicting how many total medals South Africa would win in 12 out of the 17 sports. Swimming, which was the sport in which South Africa won the majority of its medals in Delhi, features in this cluster.

Cluster 2: Performance below but proximate to the minimum forecast

The number of medals won by South Africa was one less than the minimum forecast in two instances in terms of gold medals and for one sport (weightlifting) in terms of total medals.

Cluster 3: Performance below the minimum forecast by at least two medals

In athletics, the forecast was for South Africa to achieve a minimum of four gold medals whereas the actual number was two. In terms of total medals, performance was at least two medals below the minimum forecast for three sports (athletics, boxing and shooting) and overall. Athletics and shooting emerged as the sports in which South Africa most underperformed relative to the total medal forecast.

Cluster 4: Performance at least two medals above the maximum forecast

The actual performance in lawn bowls exceeded the expected maximum performance by two gold medals. A similar outcome was observed in wrestling in terms of total medals.

According to the forecast, South Africa would win a gold medal in six sports and a medal of any colour in eleven sports. The matrix in Fig. 1 identifies the forecasted performance in the individual sports versus actual medal success in those sports. The top left quadrant of the matrix highlights sports in which South African athletes were not expected to win a medal and did not win a medal. The top right quadrant corresponds to sports in which medal success was not predicted but occurred. Looking at the top two quadrants, South Africa did not win any medals in the sports where success was not predicted. In other words, the forecast correctly predicted the sports in which South Africa would not win a gold medal and any medal.

Sports that South Africa was forecasted to medal in that did and did not materialise appear in the bottom left and bottom right quadrants respectively. The accuracy in predicting sports in which South Africa would medal varied between the gold and total medal forecasts. For sports where a gold medal was predicted, the forecast accuracy was $50 \%$ ( 3 out of 6 sports). The corresponding statistic for total medals was $64 \%$ ( 7 out of 11 sports).

\section{Conclusion}

Attempting to forecast the likely performance of a non-host nation competing away from home in a major multi-nation sports event has 
TABLE I. South Africa's predicted and actual performance in Delhi 2010

\begin{tabular}{|c|c|c|c|c|c|c|}
\hline \multirow[b]{3}{*}{ Sport } & \multicolumn{3}{|c|}{ Gold medals } & \multicolumn{3}{|c|}{ Total medals } \\
\hline & \multicolumn{2}{|c|}{ Predicted range } & \multirow[t]{2}{*}{ Actual } & \multicolumn{2}{|c|}{ Predicted range } & \multirow[t]{2}{*}{ Actual } \\
\hline & Min & Max & & Min & Max & \\
\hline Athletics & 4 & 5 & 2 & 11 & 12 & 5 \\
\hline Badminton & 0 & 0 & 0 & 0 & 0 & 0 \\
\hline Boxing & 1 & 1 & 0 & 2 & 3 & 0 \\
\hline Cycling & 0 & 0 & 0 & 0 & 1 & 0 \\
\hline Diving & 0 & 0 & 0 & 0 & 0 & 0 \\
\hline Gymnastics & 0 & 0 & 0 & 0 & 1 & 1 \\
\hline Hockey & 0 & 0 & 0 & 0 & 0 & 0 \\
\hline Lawn bowls & 0 & 1 & 3 & 1 & 3 & 3 \\
\hline Netball & 0 & 0 & 0 & 0 & 0 & 0 \\
\hline Rugby 7s & 0 & 0 & 0 & 0 & 1 & 1 \\
\hline Shooting & 0 & 1 & 0 & 4 & 9 & 0 \\
\hline Squash & 0 & 0 & 0 & 0 & 0 & 0 \\
\hline Swimming & 5 & 7 & 7 & 11 & 17 & 16 \\
\hline Table tennis & 0 & 0 & 0 & 0 & 0 & 0 \\
\hline Weightlifting & 0 & 0 & 0 & 1 & 1 & 0 \\
\hline Wrestling & 0 & 0 & 0 & 3 & 3 & 5 \\
\hline Other $^{*}$ & 1 & 1 & 0 & 2 & 2 & 2 \\
\hline Overall & 12 & 15 & 12 & 40 & 43 & 33 \\
\hline
\end{tabular}

The predicted range for each sport above is based on the minimum and maximum medal forecast for that sport across the three forecast scenarios. However, the 'overall' predicted range reflects the combined total medal count across all sports within each individual scenario. For this reason, the minimum and maximum values for each sport may not sum to the respective 'overall' figures.

Shaded values indicate cases where values are outside the predicted range. Bold values indicate cases where values are outside $+/-1$ of the predicted range.

* Other includes archery and tennis for which forecasts were not made independently but derived from the predicted performance in the individually listed sports.

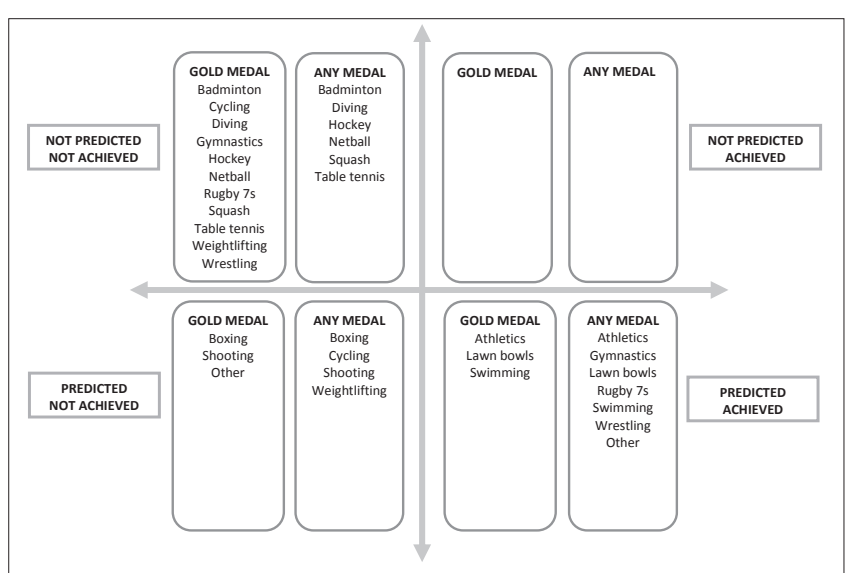

Fig. 1. Predicted versus actual medal performance for South Af rica by sport.

been an interesting experiment. The analysis of the actual performance of South African athletes in Delhi has revealed some interesting points in relation to the accuracy of the predictions. The key findings are summarised below:

- The gold medal forecast was for South Africa to achieve between 12 and 15 gold medals in Delhi. They managed to win 12 gold medals, which falls within the predicted range.

- The forecast for total medals was 40 - 43 but South Africa won 33. The lower than anticipated success in athletics and shooting explains why their total medal count was below the predicted range.

- The forecast was more accurate at identifying those sports in which South Africa would not win a gold medal or any medal compared with sports in which it would medal.

The findings from the predictive element of the research and subsequent testing have two practical implications. First, the results of this research may be of value to relevant sports authorities in South Africa to identify how their athletes fared in Delhi 2010 relative to an independent appraisal of anticipated performance. Second, the research has provided an indication of the extent to which using a nation's traditional performance in a sporting competition of international significance to predict future performance with reasonable certainty is viable. Further research with a wider sample of nations and/or the same nation over time would help to further validate the findings from this research.

\section{REFERENCES}

1. Ramchandani G, Wilson D. Forecasting South Africa's performance at the 2010 Commonwealth Games. S Afr J Sports Med 2010;22(2):42-43.

2. Bernard A, Busse M. Who wins the Olympic Games? Economic resources and medal totals. Review of Economics and Statistics 2004;6(1):413-417.

3. Bian, X. Predicting Olympic medal counts: The effects of economic development on Olympic performance. The Park Place Economist 2005; III:37-44.

4. Clarke SR. Home advantage in the Olympic Games. In: Cohen G, Lantrey T, eds. Proceedings of the Fifth Australian Conference on Mathematics and Computers in Sport. Sydney, NSW: University of Technology Sydney, 2000:43-51.

5. Shibli S, Bingham J. A forecast of the performance of China in the Beijing Olympic Games 2008 and the underlying performance management issues. Managing Leisure 2008;13:272-292. 